\title{
Matrix Metalloproteinase-9 Production following Cardiopulmonary Bypass Was Not Associated with Pulmonary Dysfunction after Cardiac Surgery
}

\author{
Tso-Chou Lin, ${ }^{1}$ Feng-Yen Lin, ${ }^{2,3}$ Yi-Wen Lin, ${ }^{4}$ Che-Hao Hsu, ${ }^{1}$ Go-Shine Huang, \\ Zhi-Fu Wu, ${ }^{1}$ Yi-Ting Tsai, ${ }^{4}$ Chih-Yuan Lin, ${ }^{4}$ Chi-Yuan Li, ${ }^{5,6}$ and Chien-Sung Tsai ${ }^{4}$ \\ ${ }^{1}$ Department of Anesthesiology, Tri-Service General Hospital, National Defense Medical Center, Taipei, Taiwan \\ ${ }^{2}$ Department of Internal Medicine, School of Medicine, College of Medicine, Taipei Medical University, Taipei, Taiwan \\ ${ }^{3}$ Division of Cardiology, Department of Internal Medicine, Taipei Medical University Hospital, Taipei, Taiwan \\ ${ }^{4}$ Division of Cardiovascular Surgery, Department of Surgery, Tri-Service General Hospital, National Defense Medical Center, \\ Taipei, Taiwan \\ ${ }^{5}$ Graduate Institute of Clinical Medical Sciences, China Medical University, Taichung, Taiwan \\ ${ }^{6}$ Department of Anesthesiology, China Medical University Hospital, Taichung, Taiwan
}

Correspondence should be addressed to Chien-Sung Tsai; sung1500@mail.ndmctsgh.edu.tw

Received 5 December 2014; Revised 8 February 2015; Accepted 9 February 2015

Academic Editor: Zhengyuan Xia

Copyright (c) 2015 Tso-Chou Lin et al. This is an open access article distributed under the Creative Commons Attribution License, which permits unrestricted use, distribution, and reproduction in any medium, provided the original work is properly cited.

Background. Cardiopulmonary bypass (CPB) causes release of matrix metalloproteinase- (MMP-) 9, contributing to pulmonary infiltration and dysfunction. The aims were to investigate MMP-9 production and associated perioperative variables and oxygenation following CPB. Methods. Thirty patients undergoing elective cardiac surgery were included. Arterial blood was sampled at 6 sequential points (before anesthesia induction, before $\mathrm{CPB}$ and at 2, 4, 6, and $24 \mathrm{~h}$ after beginning CPB) for plasma MMP-9 concentrations by ELISA. The perioperative laboratory data and variables, including bypass time, $\mathrm{PaO}_{2} / \mathrm{FiO}_{2}$, and extubation time, were also recorded. Results. The plasma MMP-9 concentrations significantly elevated at $2-6 \mathrm{~h}$ after beginning $\mathrm{CPB}(P<0.001)$ and returned to the preanesthesia level at $24 \mathrm{~h}(P=0.23)$, with predominant neutrophil counts after surgery $(P<0.001)$. The plasma MMP-9 levels at 4 and $6 \mathrm{~h}$ were not correlated with prolonged $\mathrm{CPB}$ time and displayed no association with postoperative $\mathrm{PaO}_{2} / \mathrm{FiO}_{2}$, regardless of reduced ratio from preoperative $342.9 \pm 81.2$ to postoperative $207.3 \pm 121.3 \mathrm{mmHg}(P<0.001)$. Conclusion. Elective cardiac surgery with CPB induced short-term elevation of plasma MMP-9 concentrations within 24 hours, however, without significant correlation with $\mathrm{CPB}$ time and postoperative pulmonary dysfunction, despite predominantly increased neutrophils and reduced oxygenation.

\section{Introduction}

Cardiopulmonary bypass (CPB) induces a systemic inflammatory response [1] and the following postoperative pulmonary dysfunction [2]. After initiating CPB, blood cells are activated by contact with artificial surfaces of circuits and direct contact of air and damaged tissues, resulting in release of various proinflammatory cytokines. The cessation of alveolar ventilation and ischemia-reperfusion injury leads to neutrophil activation [3] and trafficking to lung [4] and entrapment in the pulmonary capillaries. The released proteolytic enzymes, such as matrix metalloproteinase- (MMP-) 9, degrade alveolar basement membrane and matrix [5], facilitating neutrophil transmigration and protein extravasation into the interstitial tissue of lung [6]. Consequently, injury to the alveolar endothelium and alveolar-capillary barrier dysfunction as central events in the pathogenesis of acute lung injury [7] are manifested with postoperative pulmonary edema and abnormal gas exchange after cardiac surgery with $\mathrm{CPB}$. 
The MMPs are a family of more than 25 species of zinc-dependent proteases that are essential for normal tissue remodeling in processes including bone growth, wound healing, and reproduction [5]. Among them, elevated MMP9 concentration has been a risk factor for future myocardial infarction [8] or coronary revascularization [9] and heart failure [10] by myocardial remodeling [11] after acute myocardial infarction, in addition to acute lung injury [12] and chronic obstructive pulmonary disease [13]. Some clinical studies demonstrated increased MMP-9 levels following CPB for cardiac surgery $[14,15]$, however, with scarce evidence of correlation with postoperative pulmonary dysfunction, except in rat models with CPB-induced [16] or pancreatitisassociated [17] lung injury. We therefore hypothesized that MMP-9 activation following CPB may contribute to postoperative pulmonary dysfunction. The aims of this study were to investigate MMP-9 concentrations following CPB and analyze the association with perioperative variables and postoperative pulmonary parameters $\mathrm{PaO}_{2} / \mathrm{FiO}_{2}$ among patients undergoing elective cardiac surgery.

\section{Materials and Methods}

2.1. Participants. The study was approved by the ethics committee (TSGHIRB-1-101-05-115) and written informed consent was obtained from 30 patients undergoing elective cardiac surgery. Patients with cancers, patients with autoimmune diseases, patients receiving steroids, and patients with preoperative respiratory or hepatic failure were excluded.

2.2. Perioperative Management. In the operation room, patients were premedicated with fentanyl and midazolam for arterial catheterization. General anesthesia was induced with fentanyl $1.5-3 \mu \mathrm{g} / \mathrm{kg}$, propofol $0.5-1.5 \mathrm{mg} / \mathrm{kg}$, and cisatracurium $0.1-0.2 \mathrm{mg} / \mathrm{kg}$ and maintained with sevoflurane or isorfluane after tracheal intubation. A pulmonary artery catheter was placed through right internal jugular vein and transesophageal echocardiography was used to monitor realtime cardiac performance throughout the whole procedure. Routine median sternotomy and standard cardiopulmonary bypass (Sarns 8000, Terumo, Ann Arbor, MI) with an extracorporeal membrane oxygenator (Capiox SX 18, Terumo, Ann Arbor, MI) were carried out in sequence to maintain the body temperature at $28-30^{\circ} \mathrm{C}$ during surgery. The perfusionist adjusted sevoflurane or isoflurane concentration on the vaporizer to keep mean arterial blood pressure between 50 and $80 \mathrm{mmHg}$ during bypass period. Following standard rewarming and deairing, the pump was weaned at the end of the procedure. Routine inotropic support including dopamine or dobutamine infusion was added for acceptable cardiac output, if necessary. All patients were transferred to the cardiovascular surgical ICU with endotracheal intubation after surgery.

2.3. Blood Samples and Data Collection. Each $20 \mathrm{~mL}$ of arterial blood was sampled from the arterial line at 6 sequential time points (before induction, just before $\mathrm{CPB}$, and at $2 \mathrm{~h}$, $4 \mathrm{~h}, 6 \mathrm{~h}$, and $24 \mathrm{~h}$ after beginning $\mathrm{CPB}$ ) into EDTA-containing tubes. After immediate centrifugation of blood samples at speed $1500 \mathrm{rpm}$ for $10 \mathrm{~min}$ at room temperature, the plasma samples were divided into Eppendorf tubes and frozen at $-70^{\circ} \mathrm{C}$ for later plasma MMP-9 concentration testing.

Arterial blood gas analysis was routinely examined perioperatively and immediately upon ICU admission by GEM Premier 3000 (Instrumentation Laboratory, Lexington, MA). Perioperative variables, including general anesthesia, operation, and bypass times, as well as preoperative and postoperative laboratory data, were also recorded. The ratio of arterial oxygen tension $\left(\mathrm{PaO}_{2}\right.$, expressed in $\left.\mathrm{mmHg}\right)$ to inspired oxygen fraction $\left(\mathrm{FiO}_{2}\right)$ was also calculated before and after operation, as well as before extubation. The severity of hypoxemia is defined as mild $\left(200<\mathrm{PaO}_{2} / \mathrm{FiO}_{2} \leq 300 \mathrm{mmHg}\right)$, moderate $\left(100<\mathrm{PaO}_{2} / \mathrm{FiO}_{2} \leq 200 \mathrm{mmHg}\right)$, and severe $\left(\mathrm{PaO}_{2} / \mathrm{FiO}_{2} \leq 100 \mathrm{mmHg}\right)$ by the Berlin definition of acute respiratory distress syndrome [18].

2.4. Enzyme-Linked Immunosorbent Assay (ELISA). The protein concentrations of MMP-9 in the plasma were measured by using the commercially available DuoSet ELISA development kits (R\&D Systems Inc., McKinley Place N.E., Minneapolis, USA) according to the manufacturer's protocol (MMP9 catalog number DY911). The absorbance of the color at $450 \mathrm{~nm}$ was recorded using a TECAN Sunrise ELISA Reader (Tecan Group Ltd., Männedorf, Switzerland).

2.5. Statistical Analysis. The results were analyzed through SPSS software version 17 (SPSS, Chicago, IL). The demographic data, perioperative variables, postoperative leukocyte counts, arterial blood gas data, and plasma MMP-9 concentrations were presented as mean \pm SD. The correlation between MMP-9 concentrations, CPB time, and pulmonary $\mathrm{PaO}_{2} / \mathrm{FiO}_{2}$ ratios was analyzed by paired $t$-test or Pearson correlation analysis. $P$ value $<0.05$ was considered statistically significant.

\section{Results}

Demographic data of 30 patients were summarized in Table 1, with mean CPB time $120.8 \pm 52.4 \mathrm{~min}$. The postoperative white blood cell and neutrophil counts increased significantly (Table 2), whereas lymphocyte and platelet counts decreased, as compared with the preoperative data $(P<0.001)$. The blood glucose levels were significantly elevated from $135.7 \pm$ 37.1 (range $83-221$ ) to $210.2 \pm 44.1$ (range $126-338$ ) $\mathrm{mg} / \mathrm{dL}$ postoperatively $(P<0.001)$. To examine alveolar oxygen exchange, $\mathrm{PaO}_{2} / \mathrm{FiO}_{2}$ ratio was calculated. There were only 12 patients having a preoperative ratio within $200-300 \mathrm{mmHg}$ (mild hypoxemia), while turning to 3 patients with ratio $\leq 100 \mathrm{mmHg}$ (severe hypoxemia), 16 within $100-200 \mathrm{mmHg}$ (moderate hypoxemia), and 6 within 200-300 $\mathrm{mmHg}$ (mild hypoxemia) postoperatively. The mean $\mathrm{PaO}_{2} / \mathrm{FiO}_{2}$ ratio reduced from preoperative $342.9 \pm 81.2$ (range 232.0-563.0) to postoperative $207.3 \pm 121.3$ (range 67.0-538.3) $\mathrm{mmHg}(P<$ $0.001)(n=30)$ but recovered before extubation $325.7 \pm 129.8$ (range 156.0-597.5) $\mathrm{mmHg}(P=0.456)$, with extubation time $38.0 \pm 28.6$ (range $3.5-140$ ) hours after arriving at ICU 
TABle 1: Demographic data and perioperative variables $(n=30)$.

\begin{tabular}{lcc}
\hline Gender (male/female) & $23 / 7$ & \\
Age, year & $60.0 \pm 10.5$ & $(33-80)$ \\
Height, cm & $163.9 \pm 7.3$ & $(148-179)$ \\
Weight, kg & $68.1 \pm 13.7$ & $(43-104)$ \\
Body mass index, kg/cm ${ }^{2}$ & $25.3 \pm 4.4$ & $(17.2-37.3)$ \\
General anesthesia time, min & $345.6 \pm 75.1$ & $(237-495)$ \\
Operation time, min & $290.3 \pm 67.3$ & $(184-441)$ \\
Cardiopulmonary bypass time, min & $120.8 \pm 52.4$ & $(49-281)$ \\
Aortic clamp time, min & $75.2 \pm 35.2$ & $(16-167)$ \\
Ischemic heart disease & 15 & \\
$\quad$ Coronary artery graft & $2.7 \pm 0.6$ & $(1-3)$ \\
Valvular heart disease & 12 & \\
Heart tumor & 2 & \\
Atrial septal defect & 1 & \\
Hypertension & 20 & \\
Diabetes mellitus & 10 & \\
\hline
\end{tabular}

The data were presented as mean $\pm \mathrm{SD}$ (range).

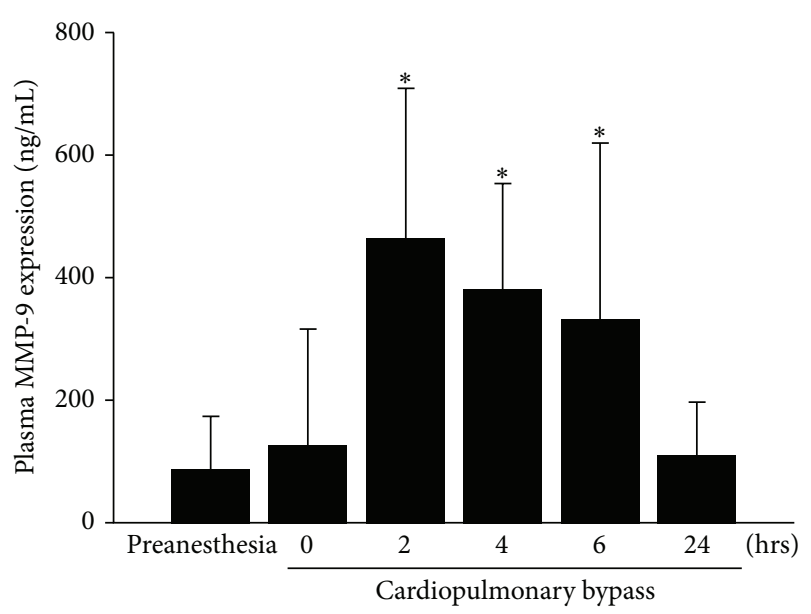

FIgURE 1: Plasma matrix metalloproteinase- 9 concentrations increased significantly at 2-6 hours after beginning cardiopulmonary bypass $(n=30)$, as compared with the preanesthesia level (all $P<0.001)$. The level returned closely to the preanesthesia level at 24 hours $(P=0.23)$.

$(n=27)$, except for 3 patients with pneumonia or mediastinitis-related septic shock, and expired at postoperative 10, 25 , and 31 days in the ICU. The mean ICU stay $(n=27)$ was $3.5 \pm 1.4$ (range $2-9$ ) days, with mean hospital stay $11.7 \pm 3.9$ (range 7-23) days after surgery.

As shown in Figure 1, the plasma MMP-9 levels $(n=30)$ rose significantly at 2, 4, and 6 hours after the start of CPB, with $462.6 \pm 247.2$ (range 65.5-1102.4), $381.1 \pm 174.3$ (range 144.1-843.8), and $331.4 \pm 288.4$ (range 19.9-1266.4) $\mathrm{ng} / \mathrm{mL}$, respectively, as compared with $85.7 \pm 88.8 \mathrm{ng} / \mathrm{mL}$ before anesthesia induction (all $P<0.001$ ). The mean level returned closely to the preanesthesia value at 24 hours after the start of CPB $(109.3 \pm 88.6 \mathrm{ng} / \mathrm{mL}, P=0.23)$.

Using Pearson correlation analysis, plasma MMP-9 concentrations at 4 and 6 hours after initiation of CPB were not correlated with $\mathrm{CPB}$ time ( $P=0.60$ and 0.83 , resp.). Besides, the MMP-9 levels at 4 hours displayed no differences between patients with less or more than 121 min CPB time $(376.6 \pm 193.3$ versus $388.8 \pm 143.9 \mathrm{ng} / \mathrm{mL}, P=0.86)$. To test the MMP-9 effect on pulmonary dysfunction, the MMP-9 levels at 4 and 6 hours were not associated with postoperative $\mathrm{PaO}_{2} / \mathrm{FiO}_{2}$ ratio $(P=0.63$ and 0.48 , resp. $)$ and neither was CPB time for $\mathrm{PaO}_{2} / \mathrm{FiO}_{2}(P=0.25)$.

\section{Discussion}

In this study, elective cardiac surgery with $\mathrm{CPB}$ induced a transient elevation of MMP-9 concentrations at 2-6 hours after beginning CPB, with a mean CPB time of 120.8 minutes. However, the MMP-9 levels at 4 and 6 hours were not correlated with the bypass time and postoperative $\mathrm{PaO}_{2} / \mathrm{FiO}_{2}$ ratio, despite predominant increase of neutrophil counts upon arriving at ICU, mostly at 4 hours after beginning $\mathrm{CPB}$.

$\mathrm{CPB}$ causes a systemic inflammatory response, including activation of neutrophils [3], which are chemoattracted to the inflammatory site. Degranulation of the inflammatory mediators from neutrophils, such as reactive oxygen species and proinflammatory cytokines, could cause pulmonary dysfunction after cardiac surgery by augmenting both neutrophilpulmonary endothelial adhesion and change of alveolarendothelial permeability [19]. Also, MMP-9 is degranulated from neutrophils to degrade type IV collagen, the major constituent of basement membrane, and to facilitate neutrophil extravasation. In a canine myocardial ischemia/reperfusion model, infiltrating neutrophils are an early source of MMP-9 after reperfusion [20]. Our previous study [14] demonstrated that intracellular MMP-9 protein and mRNA expression of neutrophils increased after beginning $\mathrm{CPB}$, consistent with the increase of plasma MMP-9 concentrations during cardiac surgery. In this study, we demonstrated a similar trend of MMP-9 production following cardiac surgery and tried to analyze the correlation between MMP-9 concentration and CPB time. With a mean 2-hour bypass period, most cardiac operations in this study were finished 2 hours thereafter. Therefore, blood samples obtained upon arriving at the ICU (mostly 4-6 hours after beginning CPB) could be an indicator for ongoing MMP-9 overproduction or remission after surgery. Among our patients, the MMP-9 concentrations at 4-6 hours were not correlated with CPB time, indicating rapid remission of MMP-9 production after elective cardiac surgery with relative shorter CPB time, despite significant increase of neutrophil counts after surgery.

Cardiac surgery using CPB may cause postoperative pulmonary dysfunction, including acute lung injury and/or acute respiratory distress syndrome (ARDS) [2]. According to the 2012 Berlin definition of ARDS [18], the severity of pulmonary dysfunction is updated by degree of hypoxemia as mild $\left(200<\mathrm{PaO}_{2} / \mathrm{FiO}_{2} \leq 300 \mathrm{mmHg}\right)$, moderate (100 $\left.<\mathrm{PaO}_{2} / \mathrm{FiO}_{2} \leq 200 \mathrm{mmHg}\right)$, and severe $\left(\mathrm{PaO}_{2} / \mathrm{FiO}_{2} \leq\right.$ $100 \mathrm{mmHg}$ ). In our patients, postoperative depression of oxygenation was observed, including reduced $\mathrm{PaO}_{2} / \mathrm{FiO}_{2}$ ratio and patients shifting from preoperative mild hypoxemia $(n=12)$ to postoperative severe $(n=3)$, moderate 
TABLE 2: Perioperative laboratory data and variables.

\begin{tabular}{|c|c|c|c|}
\hline & Preoperative & Postoperative & $P$ value \\
\hline White blood cell count, $/ \mathrm{mm}^{3}$ & $7,500 \pm 2,300$ & $11,500 \pm 4,000$ & $<0.001$ \\
\hline $\mathrm{N}$ ratio, \% & $65.4 \pm 8.6$ & $86.3 \pm 5.5$ & $<0.001$ \\
\hline $\mathrm{L}$ ratio, \% & $22.9 \pm 8.5$ & $7.8 \pm 3.2$ & $<0.001$ \\
\hline Neutrophil count, $/ \mathrm{mm}^{3}$ & $5,000 \pm 2,000$ & $10,000 \pm 3,700$ & $<0.001$ \\
\hline Lymphocyte count, $/ \mathrm{mm}^{3}$ & $1,600 \pm 600$ & $800 \pm 300$ & $<0.001$ \\
\hline Platelet, $/ \mathrm{mm}^{3}$ & $229.8 \pm 70.7$ & $152.4 \pm 38.7$ & $<0.001$ \\
\hline Hemoglobin, g/dL & $13.0 \pm 2.0$ & $10.2 \pm 1.5$ & $<0.001$ \\
\hline BUN, mg/dL & $21.4 \pm 14.5$ & $18.2 \pm 10.2$ & 0.101 \\
\hline Creatinine, mg/dL & $2.0 \pm 2.9$ & $1.6 \pm 1.9$ & 0.202 \\
\hline AST, U/L & $29.9 \pm 22.2$ & $40.7 \pm 16.8$ & 0.002 \\
\hline ALT, U/L & $29.0 \pm 23.0$ & $21.0 \pm 8.7$ & 0.027 \\
\hline Glucose, mg/dL & $135.7 \pm 37.1$ & $210.2 \pm 44.1$ & $<0.001$ \\
\hline Lactate, $\mathrm{mmol} / \mathrm{L}$ & $1.0 \pm 0.4$ & $3.2 \pm 1.9$ & $<0.001$ \\
\hline Base excess, $\mathrm{mmol} / \mathrm{L}$ & $2.2 \pm 1.9$ & $0.1 \pm 4.1$ & 0.012 \\
\hline $\mathrm{HCO}_{3}{ }^{-}, \mathrm{mmol} / \mathrm{L}$ & $25.7 \pm 2.2$ & $25.2 \pm 3.5$ & 0.466 \\
\hline Troponin-I, ng/mL & & $3.7 \pm 2.8$ & \\
\hline B-type natriuretic peptide, $\mathrm{pg} / \mathrm{mL}$ & & $213.1 \pm 242.2$ & \\
\hline Cardiac index, $\mathrm{L} / \mathrm{min} / \mathrm{m}^{2}$ & & $3.3 \pm 1.1$ & \\
\hline $\mathrm{PaO}_{2} / \mathrm{FiO}_{2}$ ratio, $\mathrm{mmHg}$ & $342.9 \pm 81.2$ & $207.3 \pm 121.3$ & $<0.001$ \\
\hline $\mathrm{PaO}_{2} / \mathrm{FiO}_{2}$ ratio before extubation & & $325.7 \pm 129.8$ & $0.456^{*}$ \\
\hline Extubation time, hours & & $38.0 \pm 28.6$ & \\
\hline ICU stay, days & & $3.5 \pm 1.4$ & \\
\hline Hospital stay, days & & $11.7 \pm 3.9(7-23)$ & \\
\hline
\end{tabular}

${ }^{*}$ Compared with the preoperative data.

( $n=16)$, and mild $(n=6)$ hypoxemia. Based on the previous evidence of predominant neutrophil recruitment and activation following CPB $[6,14]$, neutrophil-mediated MMP-9 activation [14, 20], and MMP-involved acute lung injury $[7,12]$, we hypothesized that MMP-9 activation may contribute to pulmonary dysfunction following $\mathrm{CPB}$, which could be manifested by reduced $\mathrm{PaO}_{2} / \mathrm{FiO}_{2}$ ratio. Eventually, our results demonstrated transient enhancement of MMP-9 concentrations at 4-6 hours following CPB, which, however, was not correlated with reduced postoperative $\mathrm{PaO}_{2} / \mathrm{FiO}_{2}$, indicating clinically short-term and insignificant influence on pulmonary function in our patients with elective cardiac surgery.

Two limitations should be addressed. First, only the plasma MMP-9 concentrations and clinical parameters were analyzed during the acute phase in this study, needing further ex vivo or experimental data to verify the biological changes of acute lung injury and the following myocardial remodeling. Second, limited case number in this study may diminish the clinical manifestation and its significance of correlation. More participants with various groups of severity are needed to verify MMP-9 as a clinical indicator for pulmonary dysfunction after cardiac surgery.

In conclusion, we identified that elective cardiac surgery with CPB induced a short-term elevation of MMP-9 concentrations at 2-6 hours after beginning CPB, with predominant increase of neutrophils. The postoperative MMP-9 levels upon arriving at ICU were not correlated with bypass time and reduced oxygenation after cardiac surgery.

\section{Conflict of Interests}

The authors declare that there is no conflict of interests regarding the publication of this paper.

\section{Authors' Contribution}

Chi-Yuan Li and Chien-Sung Tsai contributed equally to this work.

\section{Acknowledgments}

The authors gratefully acknowledge the research assistants, Jui-Chi Tsai, Ph.D., and Hsin-Hua Chung, for laboratory analysis. Grant support from Taiwan Ministry of Science and Technology (NSC102-2314-B-016-026 and MOST 103-2314B-016-022-MY3) and Tri-Service General Hospital (TSGHC103-028 and TSGH-C95-46) is also acknowledged.

\section{References}

[1] O. J. Warren, A. J. Smith, C. Alexiou et al., "The inflammatory response to cardiopulmonary bypass: part 1 -mechanisms of 
pathogenesis," Journal of Cardiothoracic and Vascular Anesthesia, vol. 23, no. 2, pp. 223-231, 2009.

[2] E. Apostolakis, K. S. Filos, E. Koletsis, and D. Dougenis, "Lung dysfunction following cardiopulmonary bypass," Journal of Cardiac Surgery, vol. 25, no. 1, pp. 47-55, 2010.

[3] M. Kolackova, J. Krejsek, V. Svitek et al., "The effect of conventional and mini-invasive cardiopulmonary bypass on neutrophil activation in patients undergoing coronary artery bypass grafting," Mediators of Inflammation, vol. 2012, Article ID 152895, 8 pages, 2012.

[4] J. Rossaint, C. Berger, H. van Aken et al., "Cardiopulmonary bypass during cardiac surgery modulates systemic inflammation by affecting different steps of the leukocyte recruitment cascade," PLoS ONE, vol. 7, no. 9, Article ID e45738, 2012.

[5] R. P. Iyer, N. L. Patterson, G. B. Fields, and M. L. Lindsey, "The history of matrix metalloproteinases: milestones, myths, and misperceptions," The American Journal of Physiology-Heart and Circulatory Physiology, vol. 303, no. 8, pp. H919-H930, 2012.

[6] T. Kotani, Y. Kotake, H. Morisaki et al., "Activation of a neutrophil-derived inflammatory response in the airways during cardiopulmonary bypass," Anesthesia and Analgesia, vol. 103, no. 6, pp. 1394-1399, 2006.

[7] Y. Aschner, R. L. Zemans, C. M. Yamashita, and G. P. Downey, "Matrix metalloproteinases and protein tyrosine kinases: potential novel targets in acute lung injury and ARDS," Chest, vol. 146, no. 4, pp. 1081-1091, 2014.

[8] B. J. Jefferis, P. Whincup, P. Welsh et al., "Prospective study of matrix metalloproteinase- 9 and risk of myocardial infarction and stroke in older men and women," Atherosclerosis, vol. 208, no. 2, pp. 557-563, 2010.

[9] K.-F. Wang, P.-H. Huang, C.-H. Chiang et al., "Usefulness of plasma matrix metalloproteinase-9 level in predicting future coronary revascularization in patients after acute myocardial infarction," Coronary Artery Disease, vol. 24, no. 1, pp. 23-28, 2013.

[10] D. R. Wagner, C. Delagardelle, I. Ernens, D. Rouy, M. Vaillant, and J. Beissel, "Matrix metalloproteinase-9 is a marker of heart failure after acute myocardial infarction," Journal of Cardiac Failure, vol. 12, no. 1, pp. 66-72, 2006.

[11] F. G. Spinale, "Myocardial matrix remodeling and the matrix metalloproteinases: influence on cardiac form and function," Physiological Reviews, vol. 87, no. 4, pp. 1285-1342, 2007.

[12] A. Davey, D. F. McAuley, and C. M. O'Kane, "Matrix metalloproteinases in acute lung injury: mediators of injury and drivers of repair," European Respiratory Journal, vol. 38, no. 4, pp. 959970, 2011.

[13] B. Brajer, H. Batura-Gabryel, A. Nowicka, B. Kuznar-Kaminska, and A. Szczepanik, "Concentration of matrix metalloproteinase-9 in serum of patients with chronic obstructive pulmonary disease and a degree of airway obstruction and disease progression," Journal of Physiology and Pharmacology, vol. 59, supplement 6, pp. 145-152, 2008.

[14] T.-C. Lin, C.-Y. Li, C.-S. Tsai et al., "Neutrophil-mediated secretion and activation of matrix metalloproteinase-9 during cardiac surgery with cardiopulmonary bypass," Anesthesia and Analgesia, vol. 100, no. 6, pp. 1554-1560, 2005.

[15] H. F. Galley, G. D. Macaulay, and N. R. Webster, "Matrix metalloproteinase-9, tissue inhibitor of metalloproteinase- 1 and tumour necrosis factor $\alpha$ release during cardiopulmonary bypass," Anaesthesia, vol. 57, no. 7, pp. 659-662, 2002.

[16] C. Wang, D. Li, Y. Qian, J. Wang, and H. Jing, "Increased matrix metalloproteinase-9 activity and mRNA expression in lung injury following cardiopulmonary bypass," Laboratory Investigation, vol. 92, no. 6, pp. 910-916, 2012.

[17] T. Keck, J. H. Balcom IV, C. Fernandez-del Castillo, B. A. Antoniu, and A. L. Warshaw, "Matrix metalloproteinase-9 promotes neutrophil migration and alveolar capillary leakage in pancreatitis-associated lung injury in the rat," Gastroenterology, vol. 122, no. 1, pp. 188-201, 2002.

[18] V. M. Ranieri, G. D. Rubenfeld, B. T. Thompson et al., "Acute respiratory distress syndrome: the Berlin definition," Journal of the American Medical Association, vol. 307, no. 23, pp. 25262533, 2012.

[19] R. Wynne and M. Botti, "Postoperative pulmonary dysfunction in adults after cardiac surgery with cardiopulmonary bypass: clinical significance and implications for practice," The American Journal of Critical Care, vol. 13, no. 5, pp. 384-393, 2004.

[20] M. Lindsey, K. Wedin, M. D. Brown et al., "Matrix-dependent mechanism of neutrophil-mediated release and activation of matrix metalloproteinase 9 in myocardial ischemia/reperfusion," Circulation, vol. 103, no. 17, pp. 2181-2187, 2001. 


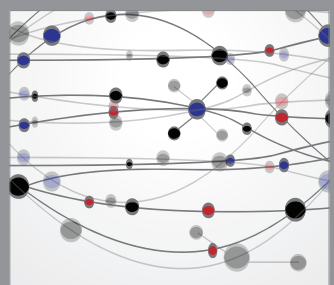

The Scientific World Journal
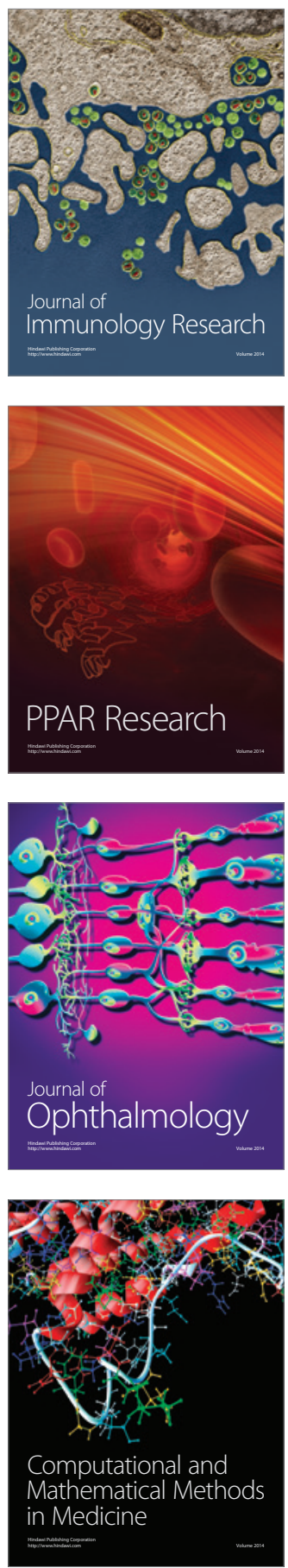

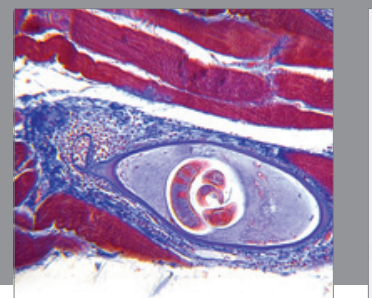

Gastroenterology

Research and Practice
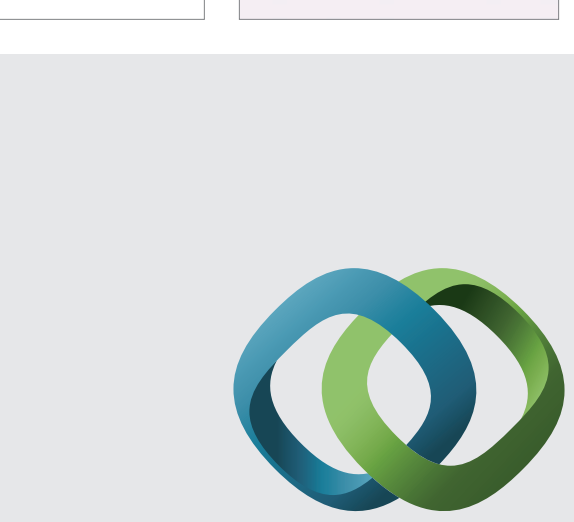

\section{Hindawi}

Submit your manuscripts at

http://www.hindawi.com
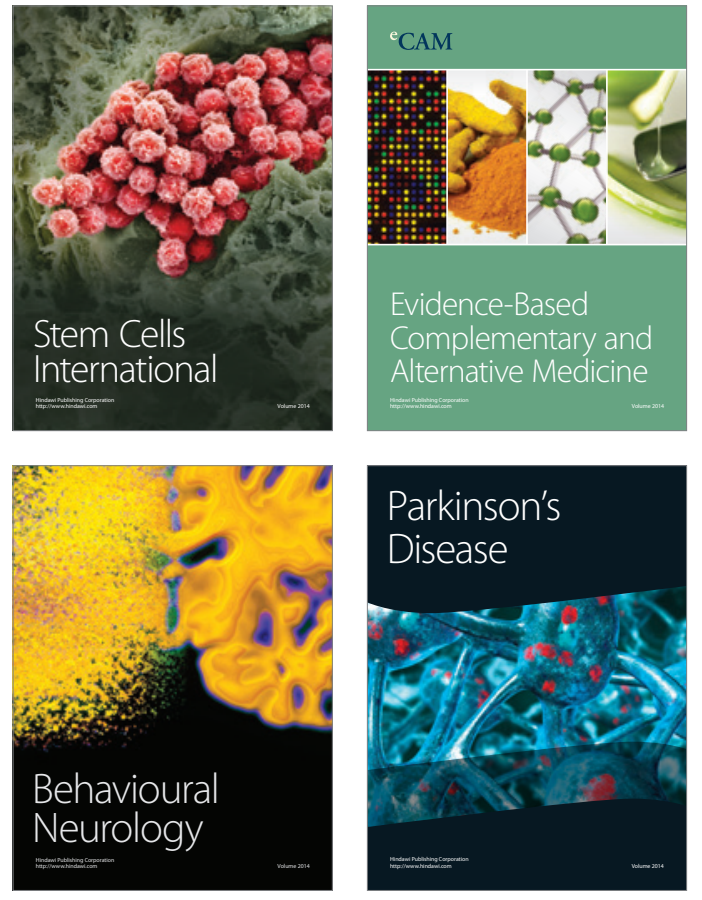
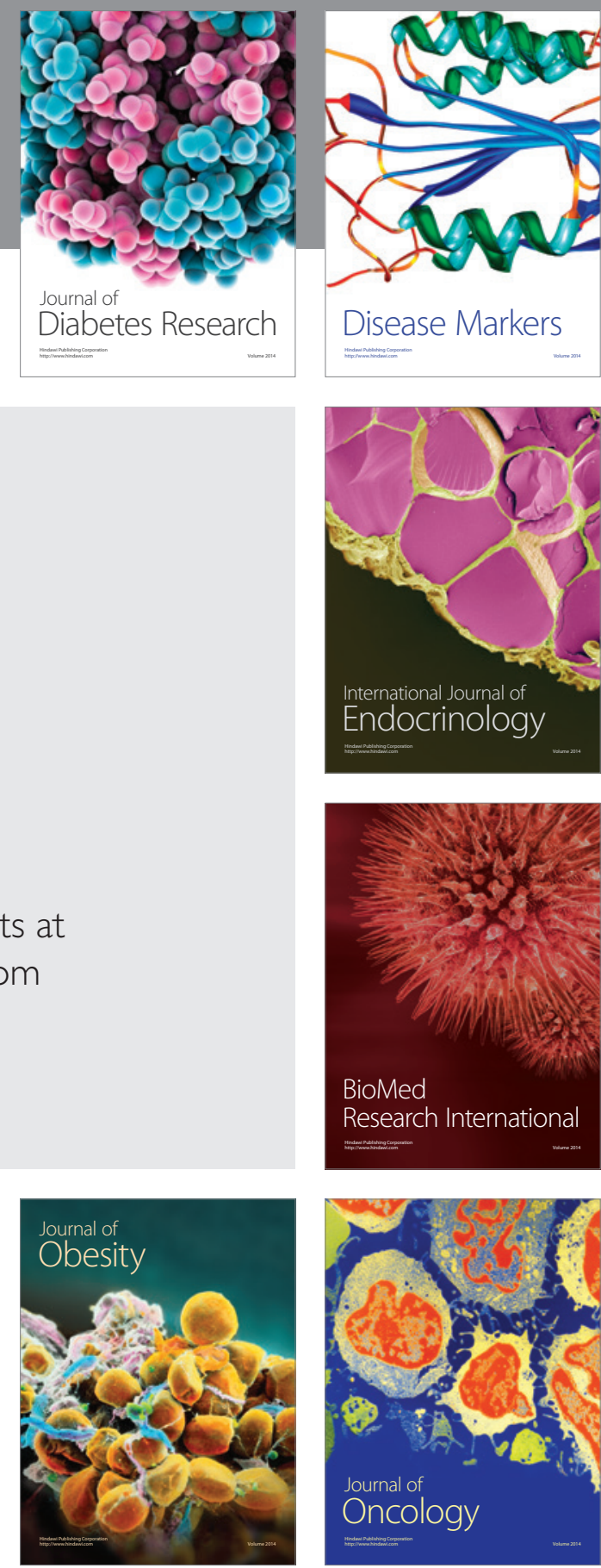

Disease Markers
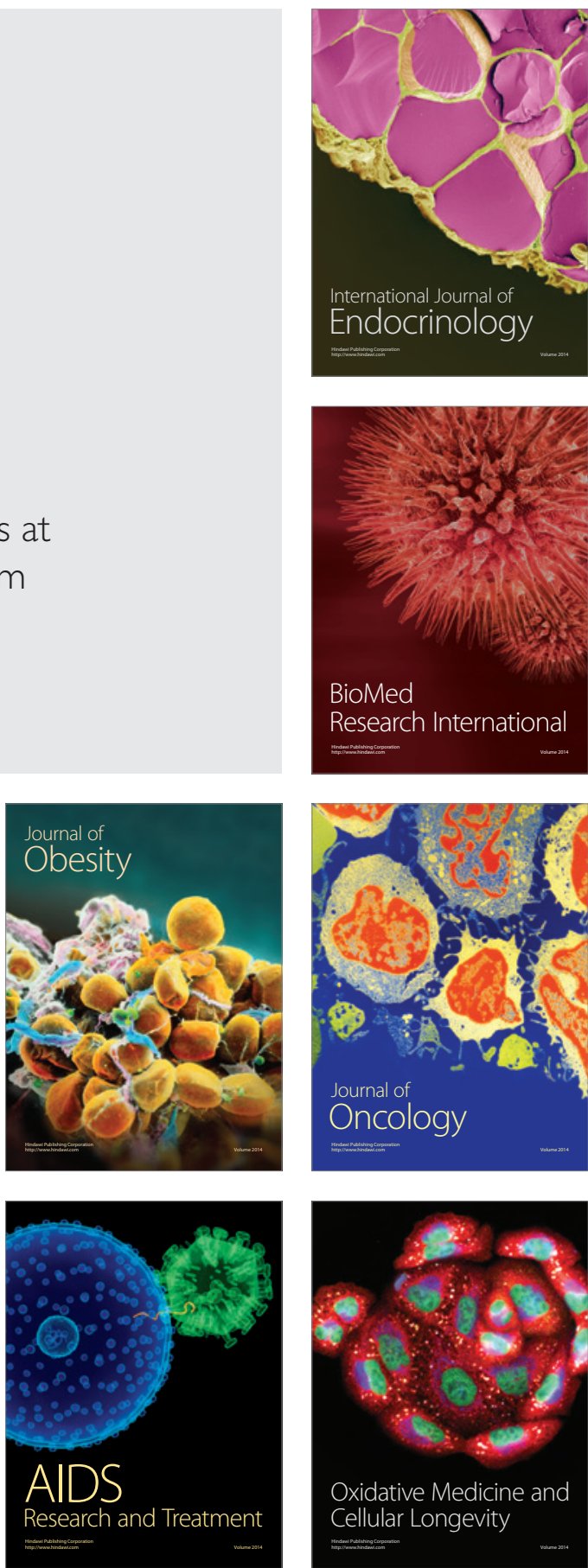